\title{
Efficacy of a trunk orthosis with joints providing resistive force on low back load during level walking in elderly persons
}

This article was published in the following Dove Press journal:

Clinical Interventions in Aging

10 November 2016

Number of times this article has been viewed

\author{
Junji Katsuhira ${ }^{1,2}$ \\ Ko Matsudaira ${ }^{2}$ \\ Hiroyuki Oka ${ }^{2}$ \\ Shinno lijima ${ }^{3}$ \\ Akihiro Ito $^{3}$ \\ Tadashi Yasui ${ }^{4}$ \\ Arito Yozu ${ }^{5}$
}

'Faculty of Medical Technology, Department of Prosthetics and Orthotics and Assistive Technology, Niigata University of Health and Welfare, Niigata, ${ }^{2}$ Department of Medical Research and Management for Musculoskeletal Pain, 22nd Century Medical and Research Center, The University of Tokyo, Tokyo, ${ }^{3}$ International University of Health and Welfare Hospital, Tochigi, ${ }^{4}$ Kawamura-Gishi Company, Ltd., Osaka, ${ }^{5}$ Department of Rehabilitation Medicine, The University of Tokyo Hospital, Tokyo, Japan
Correspondence: Junji Katsuhira Faculty of Medical Technology, Department of Prosthetics and Orthotics and Assistive Technology, Niigata University of Health and Welfare, I 398 Shimamichou, Kita-ku, Niigata 950-3198, Japan

Tel +81025257462 I

Fax +8I 025257462 I

Email katsuhira@nuhw.ac.jp
Purpose: The effects of lumbosacral and spinal orthoses on low back pain and gait are not exactly clear. We previously developed a trunk orthosis with joints providing resistive force on low back load to decrease such load, and confirmed its positive effects during level walking in healthy young adults. Therefore, we aimed to determine the efficacy of this trunk orthosis during level walking in healthy elderly subjects.

Methods: Fifteen community-dwelling elderly subjects performed level walking at a selfselected speed without an orthosis, with our orthosis, and with a lumbosacral orthosis. Kinematic and kinetic data were recorded using a three-dimensional motion analysis system, and erector spinae activity was recorded by electromyography.

Results: When comparing the three conditions, our orthosis showed the following effects: it decreased the peak extension moment, increased the peak flexion moment, decreased the lateral bending angle, increased the peak thoracic extension angle, and had significantly lower erector spinae activity and significantly larger peak pelvic forward tilt angles.

Conclusion: Our orthosis with joints providing resistive force decreased low back load and modified trunk and pelvis alignments during level walking in healthy elderly people.

Keywords: biomechanics, orthosis, gait, low back pain, joint moment, motion analysis

\section{Background}

The lifetime prevalence of low back pain (LBP) is high; 70\% of adults have had LBP at some time. ${ }^{1}$ Moreover, the number of patients with LBP in developed countries is increasing in line with the proportion of elderly., ${ }^{2,3}$

Conservative and postoperative treatments for LBP include the use of class 1 medical devices such as a lumbosacral orthosis (LSO). ${ }^{4}$ Cholewicki et al observed that one of the causes of LBP is excessive erector spinae muscle activity, which could be reduced with an LSO. ${ }^{5}$ Any decrease in the compressive force exerted on the vertebral body by reducing such activity with an LSO would benefit those with osteoporosis and vertebral compression fracture, conditions to which elderly people are vulnerable.

However, a review of data held in the Cochrane Database found no evidence for the efficacy of lumbar supports alone in preventing and treating LBP. ${ }^{6}$ Although Pfeifer et al reported that their newly designed spinal orthosis had several positive effects on muscle strength, body balance, kyphosis angle, and vital capacity in elderly patients with osteoporosis, ${ }^{7}$ to our knowledge, no previous studies have reported any significant effects of wearing a trunk orthosis to specifically decrease erector spinae activity and low back load in elderly people. To address this issue, we previously designed a trunk orthosis to improve trunk and pelvic stability and alignment by means of resistive force 


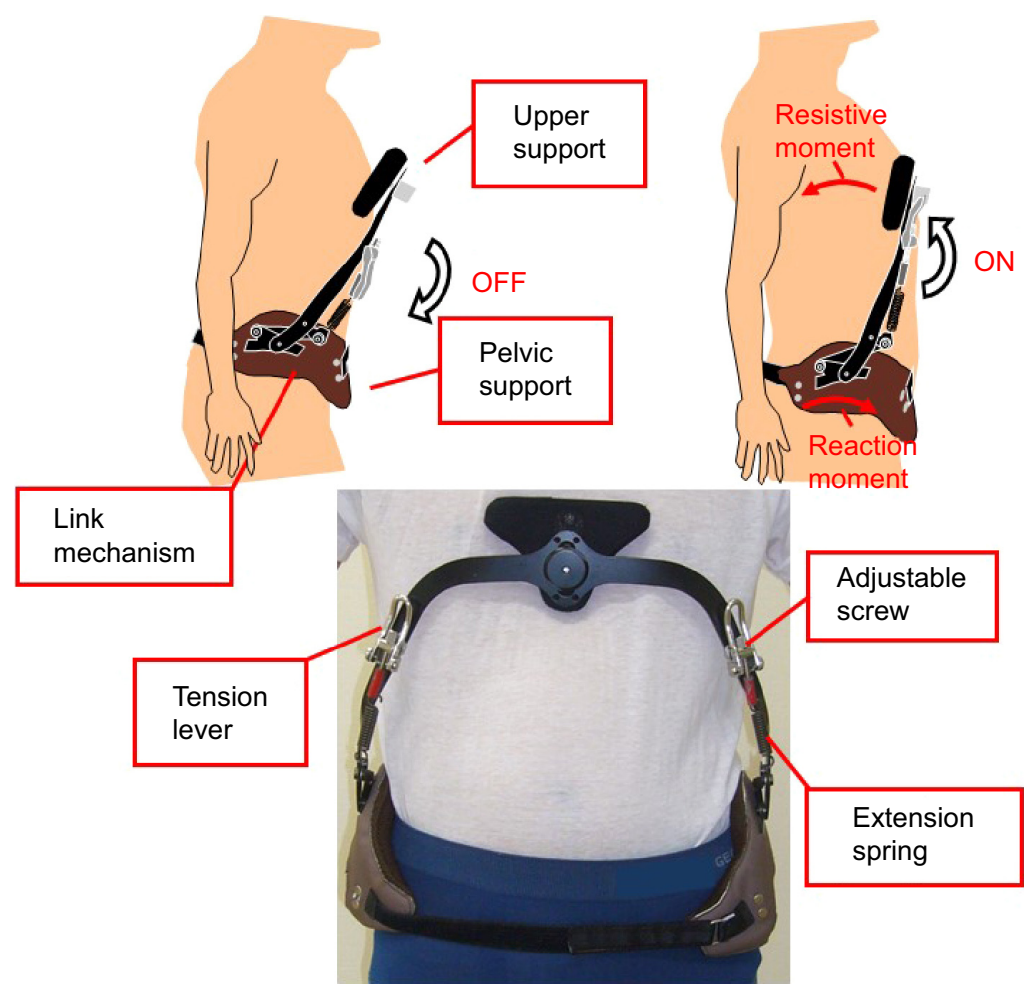

Figure I Our trunk orthosis with joints providing resistive force.

provided by joints with springs (Figure 1$){ }^{8}$ This orthosis with joints providing resistive force (ORF) creates resistive force to produce a resistive moment that rotates the trunk backward and pelvis forward. In our previous study, we reported the effect of this ORF in modifying trunk alignment and decreasing activity of the erector spinae during static standing in elderly subjects. ${ }^{9}$

A previous study reported that an LSO was effective for decreasing erector spinae activity in an unstable sitting position, where adjustment was needed to balance the upper body, ${ }^{5}$ while another study showed no positive effects of an LSO on decreasing low back load by decreasing low back muscle activity and increasing intra-abdominal pressure..$^{10}$ To date, there have been no studies on the efficacy of a typical LSO or spinal orthosis for reducing low back load during level walking, where the demands for adjusting balance are high. We previously reported that our ORF prototype increased superficial abdominal muscle activity and decreased erector spinae activity during level walking in healthy young adults, ${ }^{11}$ and here we sought to explore whether our findings can be extended to the trunk muscular activities and the low back joint moment (LBM) during level walking in healthy elderly subjects.

This biomechanics study examined the effects of the ORF on the gait of healthy elderly people during level walking and compared the effects with those obtained without an orthosis and with an LSO. We hypothesized that the ORF and LSO would both effectively decrease low back load measured by joint moment and trunk muscular activities during level walking, but that the ORF, with its biomechanical function of decreasing low back load, would show a superior effect. This follow-up to our previous study ${ }^{9}$ was performed to confirm the hypothesis that ORF might decrease low back load not only in static standing but also in level walking, using a new biomechanical method.

\section{Materials and methods Subjects}

From 31 community-dwelling elderly subjects who were candidates for this study, 15 were enrolled (all males; mean age, $67.7 \pm 6.1$ years; mean height, $162.4 \pm 5.7 \mathrm{~cm}$; mean weight, $62.3 \pm 7.8 \mathrm{~kg}$ ) after excluding those with neurological disease, pain, history of an orthopedic surgical procedure, history of orthopedic treatment within the past 5 years, and history of LBP within the past 1 year. The study subjects were the same as those of our previous study. ${ }^{9}$ The study was approved by the ethics committee of the International University of Health and Welfare (11-191). All the subjects provided written informed consent to participate.

\section{Features of the ORF}

The ORF is shown in Figure 1 and its features are described in our previous study. ${ }^{8}$ Briefly, pelvic and upper supports 
are positioned on the ileum and sternum, respectively. Stainless steel joints, connected to the upper support with a nylon pad and to the pelvic support, produce resistive force through the use of extension springs. A link mechanism translates the spring-generated tension into a resistive moment on the chest and a reaction moment on the posterior pelvis. The ORF weighs $0.99 \mathrm{~kg}$ and has a range of motion of 40 degrees. The upper support initially inclines backward to exert resistive force on the chest. The ORF has a release mechanism that releases the resistive force by pulling tension levers downward. Adjustment screws control the magnitude of the spring-generated resistive force. The ORF is currently an investigational product that has not been approved by the Food and Drug Administration or by a corresponding national agency for the indication described herein.

\section{Experimental conditions}

The subjects walked $10 \mathrm{~m}$ on a level surface at a self-selected speed in a laboratory setting under three conditions: without an orthosis, with the ORF, and with an LSO (Damen Corset, Pacific Supply, Osaka, Japan). The Damen corset was selected as it is frequently prescribed for patients with LBP. After completing three walking trials without any orthosis, they completed three trials in the two orthosis conditions in a randomized order. A minimum rest interval of 5 minutes was set between the conditions.

The subjects were allowed 5 minutes to accustom themselves to wearing the ORF and the LSO. They then practiced level walking in the laboratory before measurements were taken. Resistive force on the chest provided by the joints was measured in real time using a strain gauge (Kyowa, Tokyo, Japan) and the force data were transferred to a laptop computer by Bluetooth (Figure 2) and the force was set to a magnitude of 20-25 N during static standing. The pressure between the corset and abdomen was set to $10 \mathrm{mmHg}$ in all measurement conditions. ${ }^{12}$

\section{Experimental setup}

Gait was recorded with a three-dimensional motion capture system (Vicon 612, Vicon, Oxford, UK) consisting of six force plates (four from AMTI, Watertown, MA, USA; and two from Kistler, Winterthur, Switzerland) and 12 infrared (IR) cameras with a sampling rate of $120 \mathrm{~Hz}$. Referring to a study by Seay et al, ${ }^{13} 41$ IR-reflective markers (diameter, $14 \mathrm{~mm}$ ) were attached to each subject's body. Additionally, three markers were attached over a strain gauge and on bilateral joints of the ORF. To measure muscle activity during level walking, electromyograms (EMGs) were obtained (Biometrics, Newport, UK) at a sampling rate of $1,080 \mathrm{~Hz}$ for bilateral erector spinae ( $2 \mathrm{~cm}$ to the side between L4-L5 vertebrae). ${ }^{14}$ Maximum voluntary contraction was measured while one physical therapist manually applied resistant force to the midpoints of the bilateral scapulae, with the subject lying in the prone position on a bed.

\section{Data analysis}

During acquisition, we performed full-wave rectification feeding into a band pass filter $(20-420 \mathrm{~Hz})$ to decrease noise and used Visual 3D analytical software (C-motion, Germantown, MD, USA). The obtained EMGs were normalized using maximal voluntary contraction during isometric

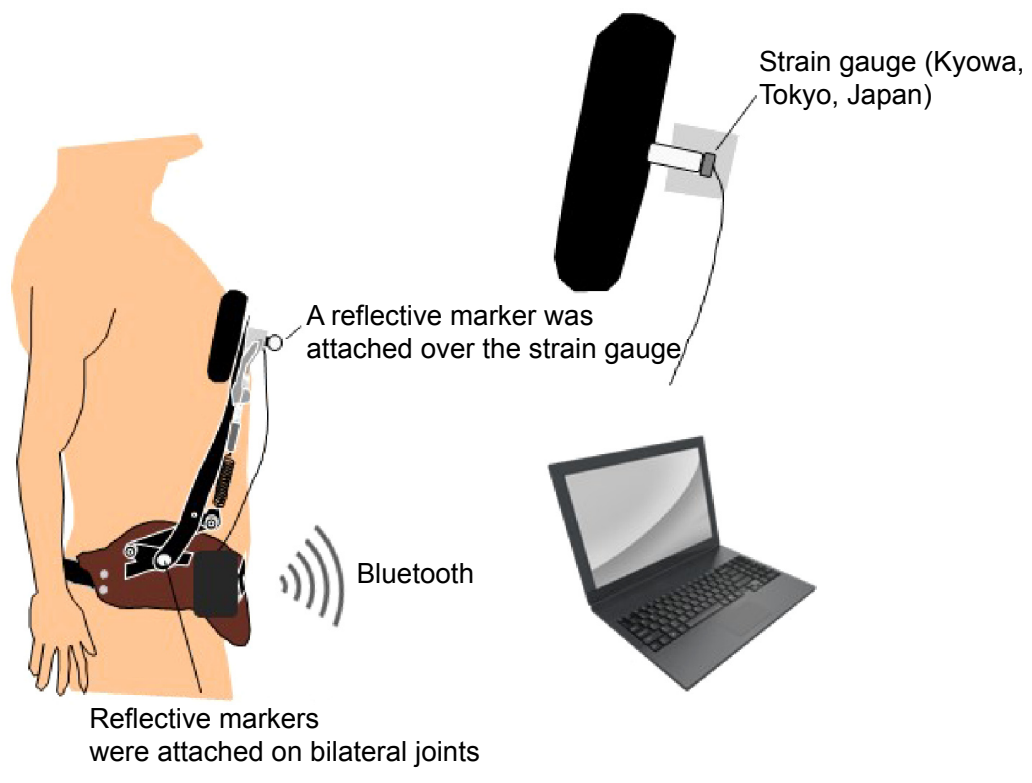

Figure $\mathbf{2}$ Trunk orthosis sensors and data transfer. 
contraction (as a percent), and the root mean square was calculated for a $50 \mathrm{~ms}$ window. Subjects performed isometric contractions in prone against gravity with maximum resistance applied by the experimenter to obtain maximal voluntary contraction of the erector spinae. ${ }^{15}$

Visual 3D was used to perform kinetic and kinematic data analysis. The obtained physical coordinates and ground reaction force data were low-pass filtered with a second-order recursive Butterworth filter, with a cutoff frequency of 6 and $18 \mathrm{~Hz}$, respectively, according to Winter's technique. ${ }^{16}$ The link segment model consisted of 13 segments: head, trunk, pelvis, bilateral upper arms, forearms, thighs, shanks, and feet. Briefly, the low back extension and flexion moments were calculated using the ground reaction force data obtained from the force plates, the reaction force on the chest obtained from the strain gauge, and the coordinates of the IR-reflective markers on the bodies of the subjects and an ORF. Moment exerted by an ORF was calculated by multiplying the force measured by a strain gate and moment arm from joint of an ORF to the force. In our previous study analyzing the ORF effect during static standing, ${ }^{9}$ we were not able to calculate LBM. The novelty of the present study lies in applying a new technique to calculate LBM during level walking while wearing an ORF. The moment was subtracted from the LBM calculated by using the ground reaction force data and the coordinates of the IR-reflective markers on the bodies of the subjects because the moment created by ORF joints equally gives forward rotation moment on the pelvis because of action-reaction law. In the analysis, segments were regarded as rigid and the joint moments were calculated using a link segment model in which segments were connected together at nodal points. To compute the joint moments, joints coordinate data were added to the ground reaction force data, in which the position of the center of mass, the weight portion, and the moment of inertia of each segment were used as parameters. The measurement data reported by Winter ${ }^{16}$ were used as the body parameters necessary for calculating the LBM. Three-dimensional trunk and pelvic angles were calculated by the Eulerian method using coordinate systems as determined by markers on the trunk and pelvis, respectively. In this study, we defined LBM and bilateral erector spinae activities among these parameters as low back load because LBM and ES activities indicate the rotation force around the low back joint and the action of the low back muscles, respectively.

\section{Statistical analysis}

Peak values of kinetic and kinematic data acquired during level walking were extracted from the phase between mid-stance and terminal stance (MTS), and the pre-swing phase in one gait cycle of the right limb because it was not possible to calculate the LBM when a subject's posterior foot did not contact the force plates (Figure 3). Integral values of EMGs were calculated during stance. Mean

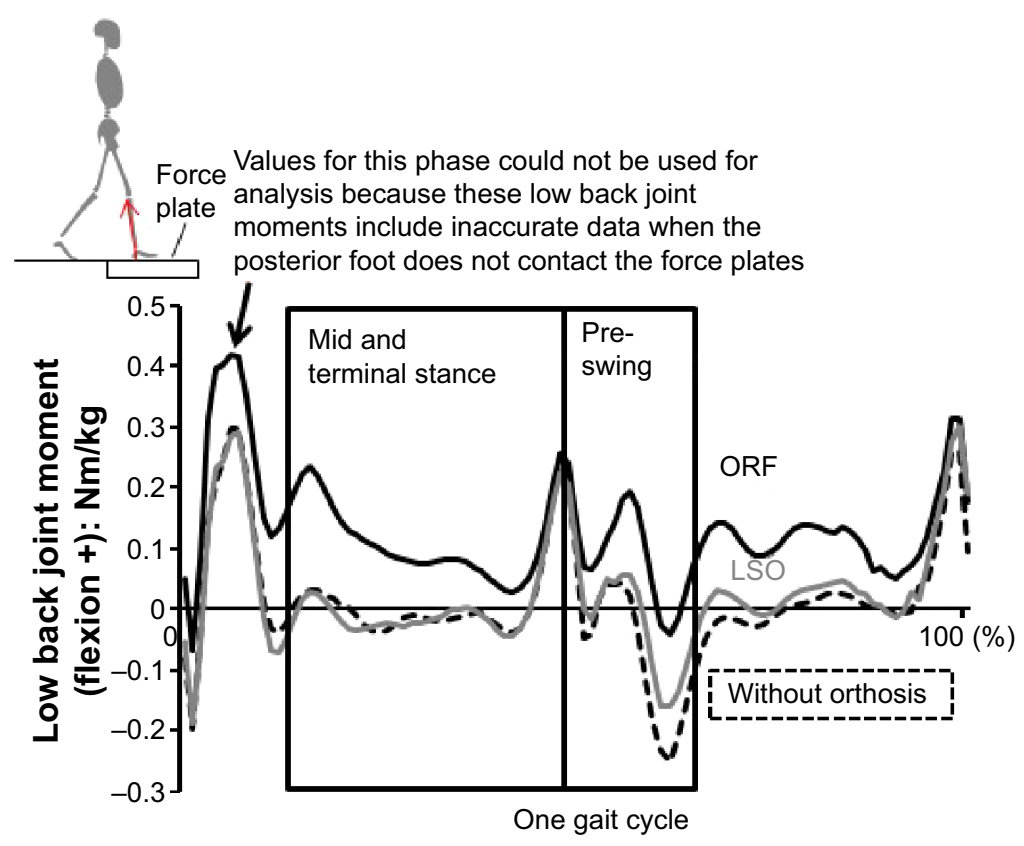

Figure 3 Average low back joint moments without orthosis (dotted line), with trunk orthosis with joints providing resistive force (ORF; solid black line), and with lumbosacral orthosis (LSO; solid gray line). 
peak values of LBM, three-dimensional trunk and pelvic angles, and integral EMGs were calculated from the data obtained in three trials and were selected as representative values for analysis. Peak LBMs were normalized by subject weight $(\mathrm{kg})$. Comparison was performed using repeated measures analysis of variance (ANOVA) after confirming non-deviation of the data and performing the Kolmogorov-Smirnov test, and variables showing a significant difference were subjected to multiple comparisons with Bonferroni correction. Significance was established at $P<0.05$. Statistical analysis was performed using SPSS 20 (SPSS Inc., Chicago, IL, USA).

\section{Results}

As shown in Tables 1 and 2, all kinematic and kinetic parameters differed significantly among the three conditions.

\section{Low back load}

Averaged LBM waveforms for all subjects in the three conditions are shown in Figure 3. The peak flexion moment was observed at the beginning of pre-swing and the peak extension moment at the end of pre-swing. Averaged waveforms of LBM and resistive force on the chest while wearing the ORF are shown in Figure 4. Force exerted on the chest was 34-37 N, which occurred during MTS and pre-swing. ANOVA indicated significant differences in the parameters showing low back load. Degrees of freedom for all data were 2 and 28. Significant main effects of an orthosis were observed for the peak flexion and extension moments not only in pre-swing but also in MTS (Table 1).
Peak extension moments in MTS and pre-swing were significantly smaller with the ORF than in the other two conditions. The peak flexion moment in MTS was significantly larger with the ORF than with the LSO; and in pre-swing was significantly larger with the ORF than in the other two conditions.

Averaged waveforms of bilateral erector spinae activity for all subjects in the three conditions are shown in Figure 5. Peak activity was observed at the beginning of pre-swing. Significant main effects of an orthosis were observed in the integral of bilateral erector spinae activity during stance (Table 1). This integral was significantly smaller with the ORF than in the other two conditions.

\section{Pelvic and thoracic angles}

Significant main effects of an orthosis were observed in peak pelvic forward tilt angles in MTS and pre-swing, and in the peak pelvic leftward rotation angle in pre-swing (Table 2). Peak pelvic forward tilt angles in MTS and preswing were significantly larger with the ORF than in the other two conditions. The peak pelvic leftward rotation angle was significantly smaller with the ORF than with the LSO.

Significant main effects of an orthosis were observed in peak thoracic extension angles in MTS and pre-swing, and in peak right and left lateral flexion angles in pre-swing. Peak extension angles in MTS and pre-swing were significantly larger with the ORF than in the other two conditions. The peak right lateral bending angle in pre-swing was significantly larger with the ORF than with the LSO. The peak left

Table I Comparison of parameters indicating low back load in three conditions during level walking in I5 healthy elderly subjects

\begin{tabular}{|c|c|c|c|c|c|c|c|}
\hline \multirow[t]{2}{*}{ Parameter of low back load } & \multicolumn{3}{|c|}{ Mean ( $95 \%$ confidence interval) } & \multirow[t]{2}{*}{ F-value } & \multicolumn{3}{|c|}{$P$-value from post-hoc test } \\
\hline & $\begin{array}{l}\text { W/O } \\
\text { orthosis }\end{array}$ & With ORF & With LSO & & $\begin{array}{l}\text { W/O orthosis- } \\
\text { with ORF }\end{array}$ & $\begin{array}{l}\text { W/O orthosis- } \\
\text { with LSO }\end{array}$ & $\begin{array}{l}\text { With ORF- } \\
\text { with LSO }\end{array}$ \\
\hline \multicolumn{8}{|l|}{ Low back joint moment $(\mathrm{Nm} / \mathrm{kg})$} \\
\hline $\begin{array}{l}\text { Peak extension moment in } \\
\text { mid and terminal stance }\end{array}$ & $\begin{array}{l}0.19 \\
(0.101-0.279)\end{array}$ & $\begin{array}{l}0.07 \\
(-0.019-0.159)\end{array}$ & $\begin{array}{l}0.22 \\
(0.126-0.314)\end{array}$ & $15.08 \mid * * *$ & 0.002 & 0.777 & 0.002 \\
\hline $\begin{array}{l}\text { Peak extension moment in } \\
\text { pre-swing }\end{array}$ & $\begin{array}{l}0.29 \\
(0.218-0.362)\end{array}$ & $\begin{array}{l}0.11 \\
(0.016-0.204)\end{array}$ & $\begin{array}{l}0.27 \\
(0.165-0.375)\end{array}$ & $17.658 * * *$ & 0.001 & 1.000 & $P<0.001$ \\
\hline $\begin{array}{l}\text { Peak flexion moment in mid } \\
\text { and terminal stance }\end{array}$ & $\begin{array}{l}0.37 \\
(0.254-0.486)\end{array}$ & $\begin{array}{l}0.49 \\
(0.363-0.617)\end{array}$ & $\begin{array}{l}0.37 \\
(0.259-0.48 I)\end{array}$ & $5.354 *$ & 0.118 & 1.000 & 0.013 \\
\hline $\begin{array}{l}\text { Peak flexion moment in pre- } \\
\text { swing }\end{array}$ & $\begin{array}{l}0.16 \\
(0.044-0.276)\end{array}$ & $\begin{array}{l}0.31 \\
(0.188-0.432)\end{array}$ & $\begin{array}{l}0.19 \\
(0.085-0.295)\end{array}$ & $28.484 * * *$ & $P<0.00$ I & 0.337 & $P<0.00$ I \\
\hline \multicolumn{8}{|l|}{ Erector spinae activity (\%IEMG) } \\
\hline $\begin{array}{l}\text { Integral of right side muscle } \\
\text { activity during stance }\end{array}$ & $\begin{array}{l}8.22 \\
(5.656-10.784)\end{array}$ & $\begin{array}{l}7.22 \\
(4.578-9.862)\end{array}$ & $\begin{array}{l}8.21 \\
(5.447-10.973)\end{array}$ & $7.459 * *$ & 0.006 & 1.000 & 0.001 \\
\hline $\begin{array}{l}\text { Integral of left side muscle } \\
\text { activity during stance }\end{array}$ & $\begin{array}{l}10.57 \\
(6.898-\mid 4.242)\end{array}$ & $\begin{array}{l}7.32 \\
(4.773-9.867)\end{array}$ & $\begin{array}{l}9.4 \\
(6 . \mid 49-12.65 I)\end{array}$ & $14.917 * * *$ & 0.001 & 0.113 & 0.015 \\
\hline
\end{tabular}

Notes: $* P<0.05, * * P<0.01$, and $* * * P<0.001$.

Abbreviations: LSO, lumbosacral orthosis; ORF, orthosis with joints providing restrictive force; W/O, without; IEMG, integral electromyogram. 
Table 2 Pelvic and thoracic angles in three conditions during level walking in 15 healthy elderly subjects

\begin{tabular}{|c|c|c|c|c|c|c|c|}
\hline \multirow[t]{2}{*}{ Angle (degrees) } & \multicolumn{3}{|c|}{ Mean ( $95 \%$ confidence interval) } & \multirow[t]{2}{*}{ F-value } & \multicolumn{3}{|c|}{$P$-value from post-hoc test } \\
\hline & $\begin{array}{l}\text { W/O } \\
\text { orthosis }\end{array}$ & With ORF & With LSO & & $\begin{array}{l}\text { W/O orthosis- } \\
\text { with ORF }\end{array}$ & $\begin{array}{l}\text { W/O orthosis- } \\
\text { with LSO }\end{array}$ & $\begin{array}{l}\text { With ORF- } \\
\text { with LSO }\end{array}$ \\
\hline \multicolumn{8}{|l|}{ Pelvic angle } \\
\hline $\begin{array}{l}\text { Peak forward tilt angle } \\
\text { mid and terminal stance }\end{array}$ & $\begin{array}{l}5.86 \\
(3.673-8.767)\end{array}$ & $\begin{array}{l}9.15 \\
(6.431-12.789)\end{array}$ & $\begin{array}{l}6.57 \\
(4.77 I-8.969)\end{array}$ & $7.701 * *$ & 0.011 & $0.84 I$ & 0.071 \\
\hline $\begin{array}{l}\text { Peak forward tilt angle in } \\
\text { pre-swing }\end{array}$ & $\begin{array}{l}4.95 \\
(2.032-7.868)\end{array}$ & $\begin{array}{l}7.85 \\
(4.195-11.505)\end{array}$ & $\begin{array}{l}5.15 \\
(2.652-7.648)\end{array}$ & $5.575^{* *}$ & 0.040 & 1.000 & 0.064 \\
\hline $\begin{array}{l}\text { Peak leftward rotation } \\
\text { angle in pre-swing }\end{array}$ & $\begin{array}{l}3.19 \\
(1.584-4.796)\end{array}$ & $\begin{array}{l}1.75 \\
(0.222-3.278)\end{array}$ & $\begin{array}{l}3.01 \\
(1.570-4.450)\end{array}$ & $4.473^{*}$ & 0.157 & 1.000 & 0.041 \\
\hline \multicolumn{8}{|l|}{ Thoracic angle } \\
\hline $\begin{array}{l}\text { Peak extension angle mid } \\
\text { and terminal stance }\end{array}$ & $\begin{array}{l}1.07 \\
(-1.007-3.147)\end{array}$ & $\begin{array}{l}2.93 \\
(0.78 I-5.079)\end{array}$ & $\begin{array}{l}1.55 \\
(-0.588-3.688)\end{array}$ & $16.373^{* * *}$ & 0.001 & 0.369 & 0.003 \\
\hline $\begin{array}{l}\text { Peak extension angle in } \\
\text { pre-swing }\end{array}$ & $\begin{array}{l}0.75 \\
(-1.498-2.998)\end{array}$ & $\begin{array}{l}2.80 \\
(0.552-5.048)\end{array}$ & $\begin{array}{l}1.45 \\
(-0.826-3.726)\end{array}$ & $16.033^{* * *}$ & 0.001 & 0.116 & 0.006 \\
\hline $\begin{array}{l}\text { Peak flexion angle in mid } \\
\text { and terminal stance }\end{array}$ & $\begin{array}{l}1.15 \\
(-0.738-3.038)\end{array}$ & $\begin{array}{l}-0.71 \\
(-2.726-1.306)\end{array}$ & $\begin{array}{l}0.47 \\
(-1.573-2.513)\end{array}$ & $12.833^{* * *}$ & $P<0.001$ & 0.288 & 0.028 \\
\hline $\begin{array}{l}\text { Peak flexion angle in } \\
\text { pre-swing }\end{array}$ & $\begin{array}{l}0.22 \\
(-1.918-2.358)\end{array}$ & $\begin{array}{l}-1.82 \\
(-3.93-0.29)\end{array}$ & $\begin{array}{l}-0.49 \\
(-2.639-1.659)\end{array}$ & $16.350 * * *$ & 0.001 & 0.117 & 0.005 \\
\hline $\begin{array}{l}\text { Peak right lateral bending } \\
\text { angle in pre-swing }\end{array}$ & $\begin{array}{l}0.64 \\
(-0.174-1.454)\end{array}$ & $\begin{array}{l}1.39 \\
(0.465-2.315)\end{array}$ & $\begin{array}{l}0.60 \\
(-0.28 I-I .48 I)\end{array}$ & $5.548 * *$ & 0.071 & 1.000 & 0.023 \\
\hline $\begin{array}{l}\text { Peak left lateral bending } \\
\text { angle in pre-swing }\end{array}$ & $\begin{array}{l}0.44 \\
(-0.479-1.359)\end{array}$ & $\begin{array}{l}-0.38 \\
(-1.277-0.517)\end{array}$ & $\begin{array}{l}0.29 \\
(-0.59|-1.17|)\end{array}$ & $6.47 \mid * *$ & 0.024 & 1.000 & 0.156 \\
\hline
\end{tabular}

Notes: $* P<0.05, * * P<0.01$, and $* * * P<0.001$.

Abbreviations: LSO, lumbosacral orthosis; ORF, orthosis with joints providing restrictive force; W/O, without.

lateral bending angle in pre-swing was significantly smaller with the ORF than in the other two conditions.

\section{Gait performance}

Walking velocity was $1.09 \pm 0.10 \mathrm{~m} / \mathrm{sec}$ without an orthosis, $1.13 \pm 0.12 \mathrm{~m} / \mathrm{sec}$ with the ORF, and $1.18 \pm 0.11 \mathrm{~m} / \mathrm{sec}$ with the LSO. Repeated measures ANOVA showed a significant main effect $(P=0.002)$. Walking velocity with the LSO was significantly faster than without an orthosis $(P=0.017)$ but was not significantly different from with the ORF.

\section{Discussion}

We hypothesized that both the LSO and ORF would effectively decrease low back load during level walking in healthy

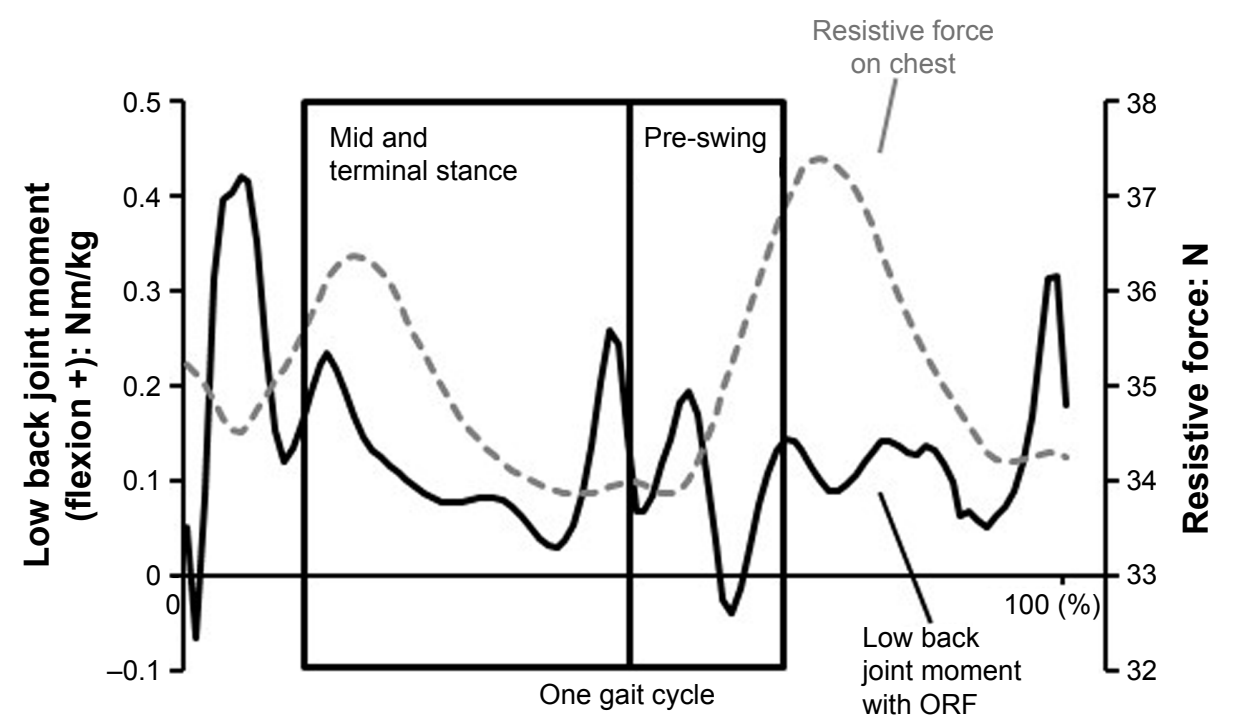

Figure 4 Average low back extension moment (solid line) and average resistive force on the chest (dotted line) with the trunk orthosis with joints providing resistive force (ORF). 

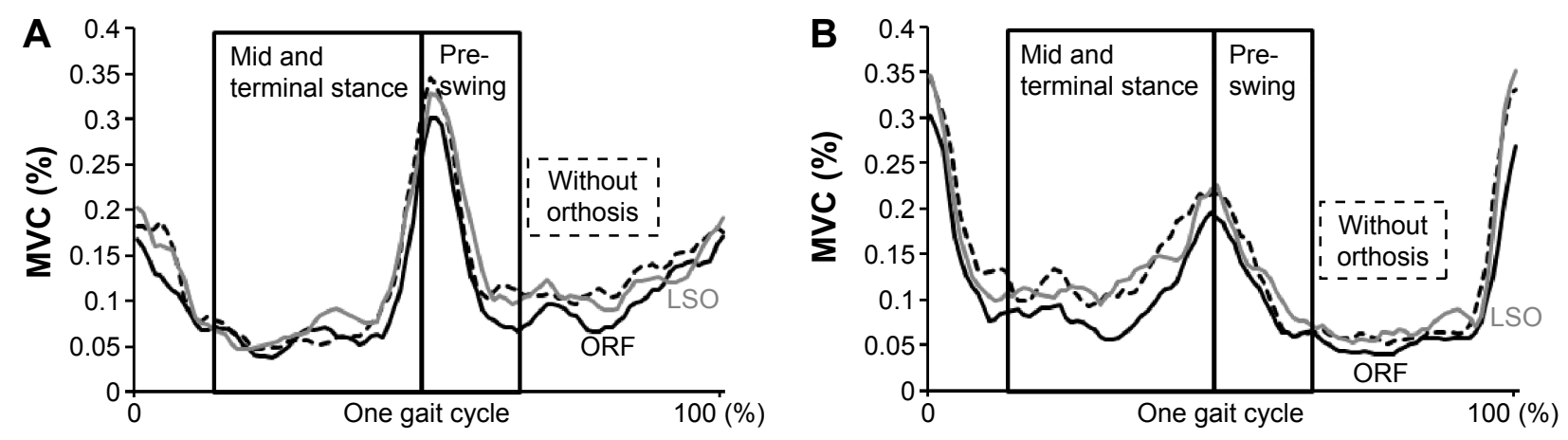

Figure 5 Right and left erector spinae activity (percent, MVC) without orthosis (dotted line), with trunk orthosis with joints providing resistive force (ORF; solid black line), and with lumbosacral orthosis (LSO; solid gray line).

Note: (A) Right erector spinae (B) Left erector spinae.

Abbreviation: MVC, maximum voluntary contraction.

elderly subjects but the ORF would have a superior effect. Our findings partially support this hypothesis. There were no significant differences between without an orthosis and with the LSO in the peak LBM and integral EMG of the erector spinae, or in the pelvic and thoracic angles. However, significant differences in all these parameters were observed with the ORF compared with no orthosis. Moreover, the low back extension moment and EMG of the erector spinae were significantly decreased with the ORF. Collectively, these results suggest that wearing the ORF during level walking should help to decrease the low back load in elderly people.

Several studies have suggested that using an LSO could stabilize the lumbosacral region but not decrease the low back load during static standing or lifting. ${ }^{10}$ Our results indicate that the same applies during level walking also. Interestingly, the ORF not only decreased the activity of the erector spinae (which has higher fatigability in patients with $\mathrm{LBP}^{17}$ ) and the low back extension moment, but also increased the low back flexion moment created by the abdominal muscles.

The biomechanical function of the ORF can be explained by a simple model (Figure 6). The ORF can produce an extension moment for the upper trunk that decreases the low back extension moment. This extension moment also produces a resistive moment on the posterior pelvis; together, these moments could improve the malalignment commonly seen in elderly people (ie, lumbar kyphosis with pelvic backward tilt). Such malalignment increases both LBP and fall risks. ${ }^{18,19}$ The extension moment served to extend the upper trunk, and the reaction moment acted as a forward rotation moment for the pelvis. In this way, the ORF increased the peak pelvic

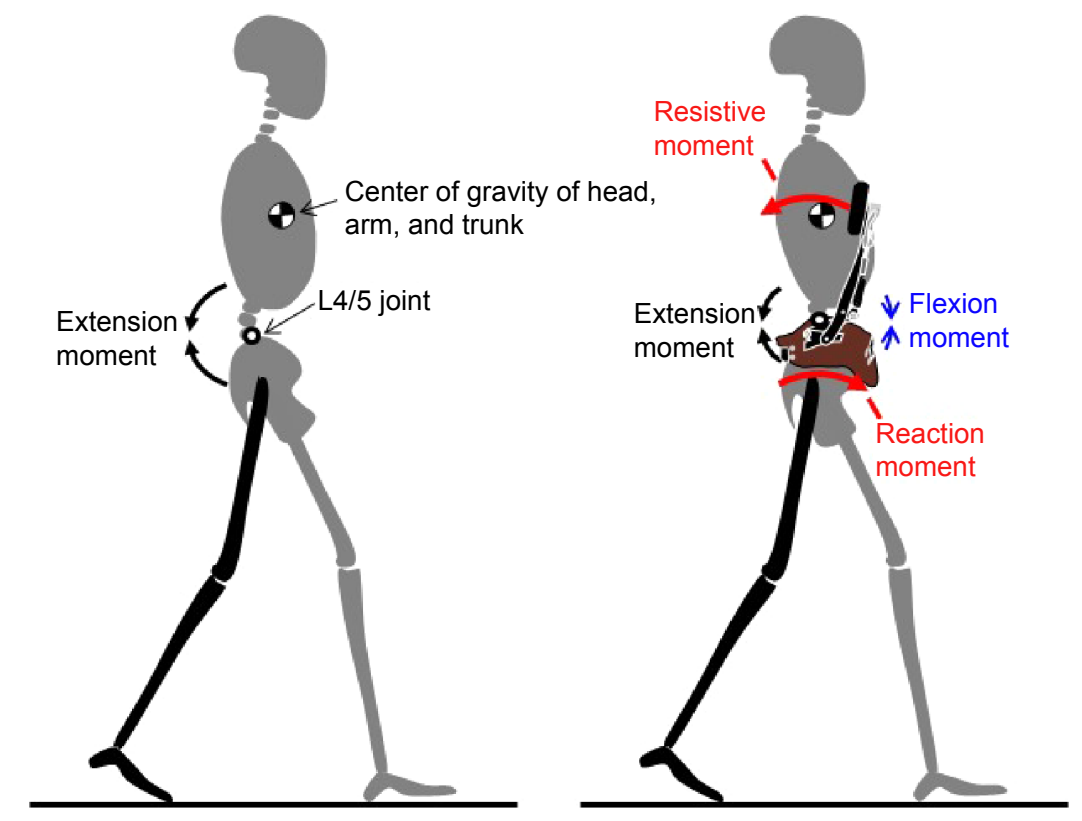

Figure 6 Biomechanical effects of the trunk orthosis with joints providing resistive force. 
forward tilt angle and peak thoracic extension angle through MTS and pre-swing. This function, which can modify alignment in the elderly, would also be beneficial for decreasing the peak LBM, because modifications to the positioning of the pelvis and thorax are directly linked to a decrease in the lever arm from the low back joint to the head, arm, and trunk center of gravity (Figure 6).

A systematic review investigating the activation pattern of trunk muscles during walking in subjects with and without LBP indicated that those with LBP exhibit higher ES activity compared with asymptomatic subjects. ${ }^{20}$ The magnitude of the decreases in erector spinae activity and the low back extension moment while wearing an ORF is relatively small. However, in daily life, people walk a large number of steps, so even though only a small decrease in low back load was evident with the ORF, the cumulative difference might have a distinct effect that can help treat and prevent LBP. ${ }^{21}$ The spinal bones of elderly people, and particularly those of patients with osteoporosis, are more fragile than the middle-aged or young. Typical orthoses would not show a biomechanical effect of decreasing low back load during level walking because most correct only the abdominal region with compressive force or support the pelvis, thorax, and lower back with small resistive force. Only one eccentric type of orthosis, the rucksack-type orthosis, was found to decrease ES activity in elderly people during level walking in a previous study. ${ }^{22}$ The rucksack-type orthosis controls the magnitude of force using weights to move the center of gravity of the upper body, thereby decreasing ES activity. This function is similar to that of the ORF, because both orthoses can control a relatively large magnitude of force applied to the upper trunk; however, the rucksack-type orthosis has the disadvantage of increasing low back compressive force in proportion to the amount of weight, which directly increases the gravitational force on the upper trunk. However, the ORF can apply resistive force horizontally to the chest, thereby avoiding an increase of low back compressive force.

An interesting feature of the ORF compared with other orthoses, including the rucksack-type, is its ability to increase the low back flexion moment produced by the abdominal muscles; the horizontally applied resistive force on the chest can not only decrease activity of the low back extension muscles using the support force, but also activate the abdominal muscles. The peak moment was larger with the ORF in MTS than with the LSO and in pre-swing than in the two other conditions. Rostami et al reported that using an LSO for 4 and 8 weeks decreased deep abdominal muscle thickness. ${ }^{23}$ Although we did not examine deep abdominal muscle activity in this study, these muscles might contribute to increasing the low back flexion moment. This effect of the ORF would be beneficial for exercises aimed at improving abdominal muscle function during level walking in elderly subjects. As we previously found a positive training effect of the ORF on such function in hemiparetic patients, ${ }^{8}$ a similar effect might be obtainable in elderly people.

A potentially negative feature of the ORF is that it limits pelvic rotation, which is one of the aspects of gait that increases step length and walking velocity. ${ }^{24}$ Although walking velocity with the ORF was not faster than that without an orthosis, it was significantly faster with the LSO than without an orthosis. Thus, the stabilization of the pelvis and thorax achieved with an LSO might improve gait performance in elderly subjects, and the limited pelvic rotation with the ORF might decrease its overall positive effect for improving gait performance.

\section{Limitations}

This study has several limitations. Wearing the ORF during level walking served to decrease low back muscle activities and joint moment, and this might be effective in the prevention and treatment of LBP. However, we did not confirm the effects of long-term ORF use. Wearing LSOs and ORFs for long periods of time might adversely affect muscle control. Only low back extension and flexion moments in the three axial moments were calculated when wearing the ORF and therefore low back compressive force, which is a strong indicator of low back load, could not be calculated because the strain gauge measured the orthogonal resistive force on the chest produced by the ORF's joints. Finally, only healthy elderly male subjects participated in this study, and only a withinsubject trial was conducted. Future studies should include healthy elderly female subjects and subjects who have LBP, and randomized controlled trials should be conducted.

\section{Conclusion}

In conclusion, we demonstrated that the ORF can decrease low back load during level walking in healthy elderly people by significantly decreasing LBM and increasing the abdominal moment. The ORF significantly modified malalignment commonly seen in elderly people. The ORF is a promising device for the prevention and treatment of LBP, and we plan to conduct randomized controlled trials with people who have LBP in the future.

\section{Acknowledgments}

This study was supported by the dissemination project of Clinical Research for Occupational Injuries and Illness from 
the Ministry of Health, Labor and Welfare of Japan, and by a KAKENHI Grant (No 23700619) from the Japan Society for the Promotion of Science.

\section{Disclosure}

The authors report no conflicts of interest in this work.

\section{References}

1. Deyo RA, Rainville J, Kent DL. What can the history and physical examination tell us about low back pain? JAMA. 1992;268:760-765.

2. Buchbinder R, Blyth FM, March LM, Brooks P, Woolf AD, Hoy DG. Placing the global burden of low back pain in context. Best Pract Res Clin Rheumatol. 2013;27:575-589.

3. Dunn KM, Hestbaek L, Cassidy JD. Low back pain across the life course. Best Pract Res Clin Rheumatol. 2013;27:591-600.

4. Cholewicki J, Lee AS, Peter Reeves N, Morrisette DC. Comparison of trunk stiffness provided by different design characteristics of lumbosacral orthoses. Clin Biomech (Bristol, Avon). 2010;25:110-114.

5. Cholewicki J, Reeves NP, Everding VQ, Morrisette DC. Lumbosacral orthoses reduce trunk muscle activity in a postural control task. J Biomech. 2007;40:1731-1736.

6. van Duijvenbode I, Jellema P, van Poppel M, van Tulder MW. Lumbar supports for prevention and treatment of low back pain. Cochrane Database Syst Rev. 2008;(2):CD001823.

7. Pfeifer M, Kohlwey L, Begerow B, Minne HW. Effects of two newly developed spinal orthoses on trunk muscle strength, posture, and quality-of-life in women with postmenopausal osteoporosis: a randomized trial. Am J Phys Med Rehabil. 2011;90:805-815.

8. Katsuhira J, Miura N, Yasui T, Takane Mitomi, Yamamoto S. Efficacy of a newly designed trunk orthosis with joints providing resistive force in adults with post-stroke hemiparesis. Prosthet Orthot Int. 2016; 40:129-136.

9. Katsuhira J, Matsudaira K, Yasui T, Iijima S, Ito A. Efficacy of a trunk orthosis with joints providing resistive force on low back load in elderly persons during static standing. Clin Interv Aging. 2016;10: 1413-1420.

10. van Poppel MN, de Looze MP, Koes BW, Smid T, Bouter LM. Mechanisms of action of lumbar supports: a systematic review. Spine. 2000;25: 2103-2113.
11. Katsuhira J, Kikkawa $\mathrm{K}$, Yasui $\mathrm{T}$, et al. Invention and evaluation of trunk brace with joints providing resistance force: measurement of activities of trunk muscles during normal gait. Bull Jpn Soc Prosthet Orthot Educ Res Dev. 2011;27:112-119.

12. Lee YH, Chen CY. Lumbar vertebral angles and back muscle loading with belts. Ind Health. 1999;37:390-397.

13. Seay J, Selbie WS, Hamill J. In vivo lumbo-sacral forces and moments during constant speed running at different stride lengths. J Sports Sci. 2008;26:1519-1529.

14. De Foa JL, Forrest W, Biedermann H. Muscle fibre direction of longissimus, iliocostalis and multifidus: landmark-derived reference lines. J Anat. 1989;163:243-247.

15. Montgomery J, Hislop H, Connelly B. Daniels and Worthingham's Muscle Testing: Techniques of Manual Examination. 8th ed. Maryland Heights, MO: Saunders/Elsevier; 2007.

16. Winter DA. Biomechanics and Motor Control of Human Movement. 4th ed. Hoboken, NJ: John Wiley \& Sons; 2009.

17. Sung PS, Lammers AR, Daniel P. Different parts of erector spinae muscle fatigability in subjects with and without low back pain. Spine $J$. 2009;9:115-120.

18. Glassman SDtsc, Bridwell K, Dimar JR, Horton W, Berven S, Schwab F. The impact of positive sagittal balance in adult spinal deformity. Spine. 2005;30:2024-2029.

19. Sinaki M, Brey RH, Hughes CA, Larson DR, Kaufman KR. Balance disorder and increased risk of falls in osteoporosis and kyphosis: significance of kyphotic posture and muscle strength. Osteoporosis Int. 2005;16:1004-1010

20. Ghamkhar L, Kahlaee AH. Trunk muscles activation pattern during walking in subjects with and without chronic low back pain: a systematic review. PM R. 2015;7:519-526.

21. Adams MA, Dolan P. Spine biomechanics. J Biomech. 2005;38: 1972-1983.

22. Ishida H, Watanabe S, Yanagawa H, Kawasaki M, Kobayashi Y, Amano Y. Immediate effects of a rucksack type orthosis on the elderly with decreased lumbar lordosis during standing and walking. Electromyogr Clin Neurophysiol. 2007;48:53-61.

23. Rostami M, Noormohammadpour P, Sadeghian AH, Mansournia MA, Kordi R. The effect of lumbar support on the ultrasound measurements of trunk muscles: a single-blinded randomized controlled trial. PM R. 2014;6:302-308.

24. Saunders JB, Inman VT, Eberhart HD. The major determinants in normal and pathological gait. J Bone Joint Surg Am. 1953;35-A:543-558.
Clinical Interventions in Aging

\section{Publish your work in this journal}

Clinical Interventions in Aging is an international, peer-reviewed journal focusing on evidence-based reports on the value or lack thereof of treatments intended to prevent or delay the onset of maladaptive correlates of aging in human beings. This journal is indexed on PubMed Central, MedLine,

\section{Dovepress}

CAS, Scopus and the Elsevier Bibliographic databases. The manuscript management system is completely online and includes a very quick and fair peer-review system, which is all easy to use. Visit http://www.dovepress. com/testimonials.php to read real quotes from published authors. 